\title{
PEMBERDAYAAN MASYARAKAT MELALUI PEMBUATAN SPAL SEDERHANA DAN HEMAT (SELAMAT) SEBAGAI INTERVENSI MASALAH SPAL DI DESA CIRANJENG KECAMATAN CINGAMBUL KABUPATEN MAJALENGKA TAHUN 2021
}

Mamlukah, Hamdan, Anisa Putriyani Maulidiyah, Dewi Andayani, Friska Oktavia Wardani

STIKes Kuningan

andayani123@gmail.com

\begin{abstract}
Abstrak
Kesehatan masyarakat sangat dipengaruhi oleh kualitas lingkungan hidupnya. Sebaliknya kualitas lingkungan hidup juga dipengaruhi oleh aktivitas masyarakat di dalamnya. Keadaan lingkungan yang optimum akan mendukung terwujudnya status kesehatan yang optimum (Mulia, 2005). Implementasi kesehatan lingkungan di Desa Ciranjeng masih dirasa kurang sehingga dapat menyebabakan masyarakat rentan terkena penyakit. Maka dari itu, diperlukan usaha-usaha untuk meningkatkan kesehatan terutama dibidang kesehatan lingkungan. Berdasarkan hasil PBL I di Desa Ciranjeng tahun 2021 cakupan KK yang memiliki masalah limbah SPAL yang dibuang ke selokan sebanyak 53,3\%. Tujuan dari penelitian ini adalah untuk meningkatkan pengetahuan dan memberikan kesadaran kepada masyarakat akan pentingnya menjaga kesehatan lingkungan terutama memilah sampah dari rumah agar tercipta lingkungan yang bersih dan sehat. Metode yang digunakan dalam kegiatan Pengalaman Belajar Lapangan II (PBL II) adalah Pengorganisasian dan Pemberdayaan Masyarakat (PPM). Hasil yang didapat berdasarkan pengolahan data pre-test dan post-test menggunakan uji Wilcoxon diperoleh hasil $p$ value adalah0,000 atau lebih kecil dari 0,05 ( $p$ value $<0,05)$, maka dapat disimpulkan bahwa ada perbedaan skor hasil sebelum dan sesudah dilakukan penyuluhan terkait Saluran Pembuangan Air Limbah (SPAL).
\end{abstract}

Kata Kunci : Desa Ciranjeng, Kesehatan Lingkungan, Pengalaman Belajar Lapangan, SPAL

\section{Pendahuluan}

Sehat adalah keadaan sempurna baik fisik, mental, sosial dan spiritual dan tidak hanya bebas dari penyakit dan kecacatan (Undang-Undang RI No. 36 Tahun 2009 Tentang Kesehatan, n.d.). 
JOURNAL OF HEALTH RESEARCH SCIENCE

VOL. 1 NO. 02, DESEMBER 2021

DOI: $\underline{10.34305 / J H R S . V 1 I 02.388}$

Tetapi belakangan WHO memodifikasi definisi sehat menjadi; sehat adalah keadaan dinamis dari fisik, mental, sosial spiritual dan tidak hanya bebas dari penyakit atau kecacatan (Swarjana, 2017). Sedangkan dalam UU Kesehatan RI No. 36 Tahun 2009 "Kesehatan adalah keadaan sehat, baik secara fisik, spiritual maupun sosial yang memungkinkan setiap orang untuk hidup produktif secara sosial dan ekonomis" (Undang-Undang RI No. 36 Tahun 2009 Tentang Kesehatan, n.d.). Kesehatan masyarakat sangat dipengaruhi oleh kualitas lingkungan hidupnya. Sebaliknya kualitas lingkungan hidup juga dipengaruhi oleh aktivitas masyarakat di dalamnya. Keadaan lingkungan yang optimum akan mendukung terwujudnya status kesehatan yang optimum (Mulia, 2005).

Aspek perilaku merupakan hal yang penting agar terwujud status kesehatan masyarakat yang semakin meningkat . Agar terwujud kesehatan masyarakat yang meningkat, maka seluruh anggota masyarakat, baik secara individu atau pribadi, anggota keluarga, anggota dari lingkungan sekolah, lingkungan kerja, dan sebagainya harus hidup dalam lingkungan yang sehat, berperilaku hidup sehat, serta mampu menjangkau pelayanan kesehatan
Ciptaan disebarluaskan di bawah

Lisensi Creative Commons Atribusi-

NonKomersial-BerbagiSerupa 4.0

Internasional.

yang bermutu, adil dan merata serta memiliki derajat kesehatan yang setinggitingginya (Maryunani, 2013).

Keadaan lingkungan dapat mempengaruhi kondisi kesehatan masyarakat. Banyak aspek kesejahteraan manusia dipengaruhi oleh lingkungan, dan banyak penyakit dapat dimulai, didukung, ditopang atau dirangsang oleh faktor- faktor lingkungan. Kesehatan lingkungan merupakan bagian dari kesehatan masyarakat yang memberi perhatian pada penilaian, pemahaman dan pengendalian dampak manusia pada lingkungan dan dampak lingkungan pada manusia (Pramudi et al., 2020).

Lingkungan adalah semua benda dan kondisi termasuk di dalamnya manusia dan aktivitasnya, yang terdapat dalam ruang di mana manusia berada dan mempengaruhi kelangsungan hidup serta kesejahteraan manusia dan jasad hidup lainnya (Hasibuan, 2016). Dalam Notoatmodjo (2007), disebutkan bahwa kesehatan lingkungan pada hakikatnya adalah suatu kondisi atau keadaan lingkungan yang optimum sehingga berpengaruh positif terhadap terwujudnya status kesehatan yang optimal pula. Ruang lingkup kesehatan lingkungan tersebut antara lain mencakup: perumahan, pembuangan kotoran manusia (tinja), 
JOURNAL OF HEALTH RESEARCH SCIENCE

VOL. 1 NO. 02, DESEMBER 2021

DOI: $\underline{10.34305 / J H R S . V 1 I 02.388}$

penyediaan air bersih, pembuangan sampah, pembuangan air kotor (air limbah), rumah hewan ternak, dan sebagainya. Adapun yang dimaksud dengan usaha kesehatan lingkungan adalah suatu usaha untuk memperbaiki atau mengoptimumkan lingkungan hidup manusia untuk terwujudnya kesehatan yang optimum bagi manusia yang hidup di dalamnya (Chandra, 2007).

Berdasarkan

perkiraan

WHO/UNICEF, sekitar $60 \%$ penduduk di kawasan pedesaan di Indonesia kekurangan akses terhadap sarana sanitasi yang pantas. Indonesia merupakan negara dengan sistem sanitasi (pengolahan air limbah domestik) terburuk ketiga di Asia Tenggara setelah Laos dan Myanmar (WHO \& UNICEF, 2020). Menurut data Status Lingkungan Hidup Indonesia dalam Kementrian Lingkungan Hidup (2003), tidak kurang dari 400.000m3/hari limbah rumah tangga dibuang langsung ke sungai dan tanah, tanpa melalui pengolahan terlebih dahulu. $61,5 \%$ dari jumlah tersebut terdapat di Pulau Jawa. Pembuangan akhir limbah umumnya dibuang menggunakan Saluran Pembuangan Akhir Limbah (SPAL) (Bolon, 2016). Berdasarkan survei pendahuluan ternyata sebagian besar masyarakat Desa Ciranjeng dengan
Ciptaan disebarluaskan di bawah

Lisensi Creative Commons Atribusi-

NonKomersial-BerbagiSerupa 4.0

Internasional.

sebagian besar mempunyai tipe saluran pembuangan limbah (SPAL) terbuka yang limbahnya dibuang begitu saja ke selokan, kebun, dan sungai. Hal ini menyebabkan bau yang cukup menyengat dan menganggu keindahan lingkungan yang tercemar oleh limbah rumah tangga yang dibuang langsung ke selokan.

Berdasarkan hasil survey dasar kesehatan masyarakat yang telah dilakukan mahasiswa program studi kesehatan masyarakat Sekolah Tinggi Ilmu Kesehatan Kuningan, diketahui bahwa banyak masyarakat yang masih membuang limbah SPAL sembarangan seperti: selokan dan kebun.

Salah satu wujud nyata dari usahausaha tersebut yaitu Praktek Belajar Lapangan (PBL) yang dilakukan oleh mahasiswa Jurusan Kesehatan Masyarakat STIKes Kuningan. Kegiatan PBL II ini merupakan salah satu wujud penerapan ilmu kesehatan masyarakat yang salah satunya adalah upaya pemecahan masalah kesehatan atau yang dikenal dengan Problem Solving Cycle. Analisis situasi sebagai tahap awal dalam upaya pemecahan masalah merupakan langkah untuk mengetahui gambaran nyata kondisi kesehatan masyarakat yang sedang dihadapi satu daerah, hingga dapat diambil tindakan 
JOURNAL OF HEALTH RESEARCH SCIENCE

VOL. 1 NO. 02, DESEMBER 2021

DOI: $\underline{10.34305 / J H R S . V 1 I 02.388}$

untuk mengatasi masalah kesehatan tersebut.

Pembuatan SPAL sederhana ini tergolong unik karena menggunakan bahan lokal yang ada di desa seperti drum, batu koral, pasir dan ijuk/ sabuk kelapa yang dapat dimasukkan kedalam lubang dengan tujuan untuk menyaring air sebelum meresap kedalam tanah. Masyarakat tidak perlu membeli bahan tersebut karena tersedia dan mudah didapatkan di Desa Ciranjeng.

\section{Metode}

Dalam kegiatan PBL II, ada beberapa tahapan yang dilakukan seperti Pemberdayaan dan Pengorganisasian Masyarakat (PPM). Pengorganisasian masyarakat dilakukan untuk mengumpulkan masyarakat di satu tempat untuk memberikan penyuluhan dan pelatihan terkait pembuatan SPAL sederhana. Pengorganisasian masyarakat dilakukan oleh ibu-ibu PKK dan kaderkader posyandu yang telah diberi informasi dan arahan oleh mahasiswa. Pemberdayaan dilakukan untuk meningkatkan kepedulain masyarakat terhadap masalah lingkungan khususnya saluran pembuangan air limbah dan merubah paradigma dalam pembuangan limbah SPAL. Seperti yang telah diketahui disebagian besar wilayah
Ciptaan disebarluaskan di bawah

Lisensi Creative Commons Atribusi-

NonKomersial-BerbagiSerupa 4.0

Internasional.

Indonesia khususnya Desa Ciranjeng, masyarakat hanya mempunyai SPAL tetapi rata-rata bentuk SPAL tersebut terbuka sehingga pembuangannya dibuang begitu saja seperti ke selokan, kebun hingga sungai. Hal tersebut dapat berpotensi menjadi masalah kesehatan karena dapat mengundang vektor penyakit. Untuk mengubah hal tersebut, mahasiswa melakukan pemberdayaan berupa penyuluhan dan pelatihan pembuatan SPAL sederhana.

Instrumen pengumpulan data adalah suatu alat bantu yang dikerjakan dalam sebuah riset untuk mengumpulkan aneka ragam informasi yang diolah secara kuantitatif dan disusun secara sistematis (Heriana, 2015). Untuk instrumen pengumpulan data kelompok kami menggunakan lembar kuesioner. Didalam kuesioner tersebut memuat data identitas responden dan beberapa pertanyaan pengetahuan tentang Saluran Pembuangan Air Limbah (SPAL).

Sementara itu, teknik pengumpulan data yang digunakan dalam kegiatan Pengalaman Belajar Lapangan II (PBL II) yaitu dengan cara memberikan lembar kuesioner (pre-test dan post-test) pada saat sebelum dan sesudah dilakukannya 
JOURNAL OF HEALTH RESEARCH SCIENCE

VOL. 1 NO. 02, DESEMBER 2021

DOI: $\underline{10.34305 / J H R S . V 1 I 02.388}$

penyuluhan mengenai masalah Saluran pembuangan Air Limbah (SPAL).

Hasil

Berdasarkan analisis kelayakan penyelesaian masalah dengan metode force field analysis diperoleh hasil bahwa bahwa alternatif pemecahan masalah yang paling tepat untuk mengatasi masalah terkait masalah SPAL di Desa Ciranjeng yaitu terdapat tiga program seperti melakukan
Ciptaan disebarluaskan di bawah Lisensi Creative Commons Atribusi-

NonKomersial-BerbagiSerupa 4.0 Internasional.

penyuluhan tentang SPAL, pembuatan SPAL Sederhana dan Hemat (SELAMAT) dan Pemasangan Media Poster.

Analisis Data Univariat

Analisis univariat bertujuan untuk mendeskripsikan karakteristik setiap variabel yang diteliti (Notoatmodjo, 2010). Dalam kegiatan ini, analisis univariat dilakukan untuk mendeskripsikan karakteristik peserta kegiatan.

Tabel 3.5 Distribusi Karakteristik Peserta Kegiatan Berdasarkan Jenis Kelamin di Desa Ciranjeng Tahun 2021

\begin{tabular}{lcc}
\hline \multicolumn{1}{c}{ Jenis Kelamin Peserta } & Frekuensi & Persentase \\
\hline Laki-laki & 7 & 35 \\
\hline Perempuan & 13 & 65 \\
\hline Total & $\mathbf{2 0}$ & $\mathbf{1 0 0}$ \\
\hline
\end{tabular}

Sumber: Hasil Pengolahan Data Sekunder,2021

Tabel 3.5 menunjukan bahwa distribusi karateristik peserta kegiatan berdasarkan jenis kelamin di desa Ciranjeng yaitu laki-laki sebanyak 7 orang dan perempuan sebanyak 13 orang. Berdasarkan table di atas dapat disimpulkan bahwa peserta kegiatan didominasi oleh peserta yang berjenis kelamin perempuan.

Tabel 3.6 Distribusi Karakteristik Peserta Kegiatan Berdasarkan Kelompok Usia di Desa Ciranjeng Tahun 2021

\begin{tabular}{ccc}
\hline Kelompok Usia Peserta & Frekuensi & Persentase (\%) \\
\hline $20-30$ & 4 & 20 \\
\hline $31-40$ & 4 & 20 \\
\hline $41-50$ & 10 & 50 \\
\hline $51-60$ & 2 & 10 \\
\hline Total & $\mathbf{2 0}$ & $\mathbf{1 0 0}$ \\
\hline
\end{tabular}


JOURNAL OF HEALTH RESEARCH SCIENCE

VOL. 1 NO. 02, DESEMBER 2021

DOI: $\underline{10.34305 / J H R S . V 1 I 02.388}$
Ciptaan disebarluaskan di bawah

Lisensi Creative Commons Atribusi-

NonKomersial-BerbagiSerupa 4.0

Internasional

Sumber: Hasil Pengolahan Data Sekunder,2021

Tabel 3.6 menunjukan bahwa distribusi karakteristik pesera kegiatan berdasarkan kelompok umur di Desa Ciranjeng mayoritas yang mengikuti kegiatan yaitu usia 41-50 tahun (50\%).

Analisis Data Bivariat

Analisis Bivariat bertujuan untuk mencari hubungan antara dua variabel yakni satu variable bebas dengan satu variabel terikat (Dahlan, 2010). Dalam kegiatan ini, analisis bivariat dilakukan untuk mengetahuai apakah ada peningkatan pengetahuan pada peserta antara sebelum dan sesudah dilakukan demonstrasi mengenai bahaya perilaku penggunaan air sungai secara langsung untuk kehidupan sehari-hari.

Analisis bivariat dilakukan dengan menggunakan uji $\mathrm{T}$ berpasangan atau uji wilcoxon. Paired T-test bertujuan untuk mengetahui apakah ada peningkatan pengetahuan peserta antara sebelum dan sesudah dilakukan penyuluhan tentang SPAL. Sedangkan uji wilcoxon digunakan sebagai alternatif apabila ada hasil yang didapat dari paired t-test tidak memenuhi syarat, yaitu apabila data tersebut tidak berdistribusi normal setelah sebelumnya dilakukan uji normalitas.

Tabel 3.8 Pretest dan Post Test Kategori Pengetahuan

\begin{tabular}{lllll}
\hline $\begin{array}{l}\text { Kategori } \\
\text { Pengetahuan }\end{array}$ & Pre Test & & Post Test & \\
\cline { 2 - 5 } & Frekuensi & Persentase (\%) & Frekuensi & Persentase (\%) \\
\hline Baik & 7 & 35 & 20 & 100 \\
\hline Cukup & 9 & 45 & 0 & 0 \\
\hline Kurang & 4 & 20 & 0 & 0 \\
\hline Jumlah & $\mathbf{2 0}$ & $\mathbf{1 0 0}$ & $\mathbf{2 0}$ & $\mathbf{1 0 0}$
\end{tabular}

Sumber: Hasil Pengolahan Data Sekunder,2021

Berdasarakan tabel 3.8. menunjukan

bahwa terjadi perbedaan antara skor pretest dengan post-test pada kategori pengetahuan penyuluhan tentang SPAL di Desa Ciranjeng. Dimana pada saat sebelum diberikannya penyuluhan tentang SPAL hanya ada 7 peserta (35\%) yang berpengetahun baik, tetapi pada saat setelah diberikan penyuluhan menjadi 100\% peserta yang memiliki pengetahuan yang baik. 
Tabel 3.9 Hasil Uji Normalitas Data

\begin{tabular}{l|l|l|l|l|l|l}
\hline \multirow{2}{*}{} & \multicolumn{3}{|c|}{ Kolmogorov-Smirnov $^{\text {a }}$} & \multicolumn{3}{c}{ Shapiro-Wilk } \\
\cline { 2 - 7 } & Statistic & df & Sig & Statistic & df & Sig \\
\hline Pre Test & 0,151 & 20 & 0,200 & 0,926 & 20 & 0,130 \\
\hline Post Test & 0,408 & 20 & 0,000 & 0,664 & 20 & 0,000 \\
\hline
\end{tabular}

a. Lilliefors Significance Correction

Berdasarkan tabel 3.9 menunjukan bahwa terdapat dua $p$ value yaitu $p$ value berdasarkan Kolmogorov-smirnov dan Shapiro-Wilk. Dari kedua $p$ value tersebut, $p$ value yang diperhatikan adalah $p$ value Shapiro-Wilk karena jumlah sampel dalam kegiatan ini adalah 20 (sampel<50). Berdasarkan hasil uji normalitas tersebut $p$ value yang didapatkan pada pre-test adalah
0,130 dan post-test 0,000 atau lebih kecil dari 0,05 ( $p$ value $<0,05)$, maka dapat disimpulkan bahwa data tersebut tidak berdistribusi normal sehingga analisis data tidak dapat menggunakan Paired T-test melainkan perlu menggunakan uji alternative Wilcoxon. Adapun hasil analisis dari uji Wilcoxon tersebut dapat dilihat pada tabel berikut.

Tabel 3.10 Hasil Analisis Uji Wilcoxon (Ranks)

\begin{tabular}{l|l|l|l|l}
\hline \multicolumn{2}{c|}{} & N & Mean Rank & Sum of Ranks \\
\hline \multirow{2}{*}{ Post Test - Pre Test } & Negative Ranks & $0^{\mathrm{a}}$ &, 00 &, 00 \\
\cline { 2 - 5 } & Positive Ranks & $17^{\mathrm{b}}$ & 9,00 & 153,00 \\
\cline { 2 - 5 } & Ties & $3^{\mathrm{c}}$ & & \\
\hline & Total & $\mathbf{2 0}$ & & \\
\hline
\end{tabular}

Sumber: Hasil Pengolahan Data Primer, 2021

1. Negative ranks atau selisih (negatif) antara perolehan nilai untuk pre test dan post test pada saat penyuluhan tentang SPAL adalah 0, baik itu pada nilai $\mathrm{N}$, mean rank, maupun sum of rank. Nilai 0 ini menunujukan tidak adanya penurunan nilai post-test ke nilai pre-test.

2. Positive ranks atau selisih (positif) antara perolehan nilai untuk pre-test dan post test. Pada tabel diatas, menunjukan bahwa terdapat 17 data 
JOURNAL OF HEALTH RESEARCH SCIENCE

VOL. 1 NO. 02, DESEMBER 2021

DOI: $\underline{10.34305 / J H R S . V 1 I 02.388}$

positif $(\mathrm{N})$ yang artinya ke 17 perserta penyuluhan mengalami peningkatan nilai dari pre-test ke post test. Mean ranks atau rata-rata peningkatan tersebut adalah 9,00 sedangkan ranking positif sum of ranks adalah sebesar 153,00 .
Ciptaan disebarluaskan di bawah Lisensi Creative Commons Atribusi-

NonKomersial-BerbagiSerupa 4.0 Internasional.

3. Ties kesamaan nilai pre-test dan post test, berdasarkan nilai pada tabel diatas, terdapat 3 peserta penyuluhan yang memiliki nilai sama baik pada saat pretest maupun post test.

Tabel 3.11 Hasil Analisis Uji Wilcoxon (Test Statistic)

\begin{tabular}{l|c}
\hline & $\begin{array}{c}\text { Nilai Post-Test Peserta Kegiatan- Nilai Pre-test Peserta } \\
\text { Kegiatan }\end{array}$ \\
\hline$Z$ & $-3,638^{\mathrm{b}}$ \\
\hline Asymp. Sig. (2-tailed) & 0,000 \\
\hline
\end{tabular}

Sumber: Hasil Pengolahan Data Primer, 2021

Dasar pengambilan keputusan

dalam Uji Wilcoxon

1. Jika nilai Asymp. Sig. (2-tailed) lebih kecil dari <0,05, maka $\mathrm{Ha}$ diterima.

2. Jika nilai Asymp. Sig. (2-tailed) lebih besar dari $>0,05$ maka $\mathrm{Ha}$ ditolak.

Hipotesis telah dibuat

Ha : Terdapat hubungan antara pemberian penyuluhan dengan tingkat pengetahuan masyarakat Desa Ciranjeng

HO : Tidak terdapat hubungan antara pemberian penyuluhan dengan tingkat pengetahuan masyarakat Desa Ciranjeng

\section{Pembahasan}

Berdasarkan tabel 3.11 menunjukan Asymp. Sig. (2-tailed) bernilai 0,000. Karena nilai 0,000 lebih kecil dari 0,05 maka dapat disimpulkan bahwa "Ha diterima”. Artinya terdapat perbedaan antara perolehan nilai peserta penyuluhan tentang SPAL pada Pre test dan Post test, sehingga dapat disimpulkan pula bahwa "Terdapat pengaruh penyuluhan terhadap tingkat pengetahuan masyarakat desa Ciranjeng". Hasil penelitian ini sejalan dengan Ondang et al. (2021). Salah satu strategi untuk perubahan perilaku adalah pemberian informasi guna meningkatkan pengetahuan sehingga timbul kesadaran 
JOURNAL OF HEALTH RESEARCH SCIENCE

VOL. 1 NO. 02, DESEMBER 2021

DOI: $10.34305 /$ JHRS.V1I02.388

yang pada akhirnya orang akan berperilaku sesuai dengan pengetahuannya tersebut. Dan salah satu upaya pemberian informasi yang dapat dilakukan adalah penyuluhan (Aziza et al., 2020).

\section{Kesimpulan Dan Saran}

Berdasarkan analisis kelayakan penyelesaian masalah dengan metode force field analysisdiperoleh bahwa hasil alternatif pemecahan masalah yang paling tepat dalam mengatasi masalah pembuangan limbah SPAL sembarangan di Desa Ciranjeng melalui penyuluhan terkait SPAL dan pembuatan SELAMAT (SPAL Sederhana dan Hemat).

Berdasarkan pengolahan data pretest dan post test menggunakan $U j i$ Wilcoxon diperoleh nilai $p$ value sebesar 0,000 atau lebih kecil dari 0,05 ( $p$ value $<0,05)$, maka dapat disimpulkan bahwa ada perbedaan skor hasil sebelum dan sesudah dilakukan penyuluhan terkait Saluran Pembuangan Air Limbah (SPAL).

\section{Daftar Pustaka}

Aziza, N., Mega, N., Julia, B., \& Abidin, Z. (2020). Pengaruh Penyuluhan Kesehatan Tentang PHBS dalam Menggunakan Air Bersih Terhadap Kebersihan dan Kesehatan Rumah Tangga di Desa Sidoasih Kabupaten Lampung Selatan. Kampurui Jurnal Kesehatan Masyarakat, 2(2), 43-47.
Ciptaan disebarluaskan di bawah

Lisensi Creative Commons Atribusi-

NonKomersial-BerbagiSerupa 4.0

Internasional

Bolon, C. M. T. (2016). Gambaran FaktorFaktor Penyebab Keluarga Membuang Air Limbah Sembarangan Di Lingkungan 24 Kelurahan Pulo Brayan Kota Kecamatan Medan Barat Tahun 2015. Jurnal Ilmiah Keperawatan IMELDA, 2(1), 64-67.

Chandra, B. (2007). Pengantar Kesehatan Lingkungan (P. Widyastuti (ed.)). ECG.

https://opac.perpusnas.go.id/DetailOp ac. $\operatorname{aspx} ? \mathrm{id}=549002$

Dahlan, S. (2010). BESAR SAMPEL DAN CARA PENGAMBILAN SAMPEL Dalam Penelitian Kedokteran Dan Kesehatan (3rd ed.). Salemba Medika. https://onesearch.id/Record/IOS3359. slims-61

Hasibuan, R. (2016). Analisis Dampak Limbah/Sampah Rumah Tangga Terhadap Pencemaran Lingkungan Hidup. Ilmiah, 04(01), 42-52.

Kementrian Lingkungan Hidup. (2003). Revitalisasi Indikator Sosial Dan Lingkungan .

http://perpustakaan.menlhk.go.id/pust aka/home/index.php?page $=$ ebook\&co $\mathrm{de}=$ plh\&view $=$ yes \&id $=1389$

Maryunani, A. (2013). Perilaku Hidup Bersih dan Sehat (PHBS). Mitra Media Pustaka.

Mulia, R. M. (2005). Kesehatan lingkungan. Graha Ilmu.

Notoatmodjo, S. (2007). Kesehatan Masyarakat Ilmu dan Seni. In Rineka Cipta. Rineka Cipta.

Notoatmodjo, S. (2010). Ilmu perilaku kesehatan. 
JOURNAL OF HEALTH RESEARCH SCIENCE

VOL. 1 NO. 02, DESEMBER 2021

DOI: $10.34305 / \mathrm{JHRS} . \mathrm{V} 1 \mathrm{I} 02.388$

Ondang, M. M., Engkeng, S., \& Raule, J. H. (2021). Pengaruh Penyuluhan Kesehatan Terhadap Perilaku Masyarakat Dalam Pengelolaan Sampah Di Desa Kaneyan Kecamatan Tareran Kabupaten Minahasa Selatan. Kesmas, 10(3), 82-88.

Pramudi, A., Nadiroh, \& Samadi. (2020). Ketaatan pengelolaan lingkungan industri dalam implementasi kebijakan pengendalian pencemaran udara. Sinasis, 1(1), 222-228.

Undang-Undang RI No. 36 Tahun 2009 Tentang Kesehatan. Retrieved November 29, 2021, from https://infeksiemerging.kemkes.go.id/ download/UU_36_2009_Kesehatan.p $\mathrm{df}$

Swarjana, I. K. (2017). Ilmu Kesehatan Masyarakat - Konsep, Strategi Dan Praktik/ - I Ketut Swarjana, STIKes
Ciptaan disebarluaskan di bawah Lisensi Creative Commons AtribusiNonKomersial-BerbagiSerupa 4.0 Internasional.

Bali - Google Buku (A. Ari C. (Ed.)). Penerbit Andi. https://books.google.co.id/books?hl=i $\mathrm{d} \& \mathrm{lr}=\& \mathrm{id}=\mathrm{fMQzDwAAQBAJ} \& \mathrm{oi}=\mathrm{fn}$ $\mathrm{d} \& p g=\mathrm{PA} 213 \& \mathrm{dq}=$ Bali, $+\mathrm{S} .+$ and. $+(\mathrm{n}$. d.).+"Swarjana, + I. + K. $+\% 26+$ Bali, + S. + Ilmu+Kesehatan+Masyarakat++ Konsep, + Strategi+Dan+Praktik, + Pe nerbit+Andi."\&ots=Sdb167UgXt\&sig $=$ gvu41oSw2u65-

ARjk5v_3W58pY0\&redir_esc $=\mathrm{y} \# \mathrm{v}=\mathrm{o}$ nepage \&q\&f=false

WHO, \& UNICEF. (2020). Air, Sanitasi, Higiene, dan Pengelolaan Limbah yang Tepat Dalam Penanganan Wabah COVID-19. World Health Organization, 1-10. https://www.who.int/docs/defaultsource/searo/indonesia/covid19/whounicef---air-sanitasi-higiene-danpengelolaan-limbah-yang-tepatdalam-penanganan-wabah-covid19.pdf?sfvrsn=bf12a730_2 